AJHSE Vol: 1 (2): 86-100, 2020

Article Ref. No.: AJHSE010209

Accepted Date: October 01, 2020

(C) 2020. CC License 4.0

www.ajhse.org
African Journal of Health, Safety and Environment

An official publication of the

Applied Environmental Bioscience and Public Health Research Group

University of Benin, Benin City, Nigeria

Open Access | Bi-annual | Peer-reviewed | International ISSN (Online): 2695-1819 | ISSN (Print): 2695-2386

\title{
PRIMARY HEALTH CARE IN NIGERIA: AN APPRAISAL OF THE EFFECT OF FOREIGN DONATIONS
}

\author{
*Alonge S. K.
}

*Social Policy Department, Nigerian Institute of Social and Economic Research (NISER), Ibadan, Nigeria

*Corresponding Author's E-mail: alongesk@yahoo.com

\begin{abstract}
$\mathrm{P}$ rimary Health Care (PHC) provides the most viable route towards achieving health related sustainable development goals (SDGs) and is crucial to the achievement of other SDGs. Given the importance of primary health care, nations across the world devote considerable effort and resources towards establishing and maintaining effective PHC systems. In Nigeria, domestic spending on the health sector has been declining while foreign donations towards improving primary health care have been on the increase. However, recent global trends and the imminent expiry of deadlines for a number of foreign donations point toward a not too distant future without foreign donations for health care system improvements. This constitutes a development challenge. Even though foreign donations have yielded some positive health outcomes, the effect of foreign donations on the primary health care system is unclear. The study set out to examine the amount and effect of foreign donations on the primary health care system in Nigeria. The paper combined qualitative methodology and analysis of literature to investigate the present state of primary healthcare, identify the setbacks to full development of primary healthcare in Nigeria and examined the effects of foreign donations on the primary health care system in Nigeria. The paper found that foreign donations have been increasing but have also led to the perpetuation of a non-committal attitude towards increasing domestic spending on health and the neglect of health system strengthening. Therefore, the paper recommends timely and steady increase in domestic funding for health along with the strengthening of the health system towards creating an effective primary health care system with or without foreign donations.
\end{abstract}

Keywords: primary health care, foreign donations, domestic funding

LICENSE: This article by African Journal of Health, Safety and Environment (AJHSE)is licensed and published under the Creative Commons Attribution License 4.0 International License, which permits unrestricted use, distribution, and reproduction in any medium, provided this article is duly cited.

COPYRIGHT: The Author(s) completely retain the copyright of this published article.

OPEN ACCESS: The Author(s) approves that this article remains permanently online in the open access (OA) mode.

QA: This Article is published in line with "COPE (Committee on Publication Ethics) and PIE (Publication Integrity \& Ethics)". 


\section{INTRODUCTION}

The right to enjoy the highest attainable standard of health is one of the most fundamental human rights in the constitution of the World Health Organization (World Health Organization, 2008). Therefore, all member countries of the United Nations (UN) have the mandate to provide basic, affordable and universal healthcare for their citizens. Primary Health Care (PHC) provides the most viable route towards achieving the aforementioned mandate. Primary Health Care is defined as a whole-of-society approach to health and well-being based on the needs, peculiarities and preferences of individuals, families and communities. (WHO, 2019). PHC serves as the first contact of individuals, families and communities with the national health system. Accessibility to and closeness to the poor and hard to reach populace makes the primary health care system the most relevant, unique and important in the three-tier health system in Nigeria, as indeed stressed by the World Health Organization (WHO, 2018). Primary healthcare is a deliberate and systematic effort to develop a health care system that caters to the needs of majority populations and poor citizens, at an affordable and sustainable cost and with a guarantee of quality health care service through government primary health care centres and faith-based clinics in rural and suburban areas, while secondary and tertiary health facilities serve urban populations. The primary healthcare system is designed to be cost effective and designated as the first point of call for all, irrespective of the social or economic status.

PHC provides healthcare from the cradle to the grave for the individual by focusing on broad and inclusive determinants of health and through the provision of comprehensive care, promotion of health friendly practices through health education, prevention and treatment of infectious and non-infectious diseases, public health management as well as rehabilitation and palliative care for all persons. Primary health care is extremely important for the continued existence of humankind in general and for the growth and development of nations. By treating people and communities as stakeholders and duty bearers in their well-being and total health outcomes, the PHC systems is capable of responding locally and promptly to rapid economic, demographic and technological changes with proven potential to yielded massive benefits across the world (WHO, 2008).

PHC has also been found to be highly effective and efficient in treating the main causes and risk factors of health deficiencies. It is also capable of tackling emerging threats to public health and wellbeing into the future. Primary health care is crucial for the realization of health-related Sustainable Development Goals (SDGs) which are in turn inextricably linked with the other SDGs such as ending poverty, inclusive education, work and economic growth, reducing inequality and climate action.

Given the importance of Primary health care, nations across the world devote considerable efforts and resources towards establishing and maintaining viable PHC systems. As a signatory to the United Nations' Charter and member of the World Health Organization (WHO), Nigeria has the mandate to do same and indeed has made

efforts to provide primary healthcare to its citizens. It is worthy of note that the success of efforts to provide effective primary healthcare depend on a good choice and combination of adequate and efficient method (s) of financing and on a sound framework for the organization and delivery of health services (Drouin, 2007). Healthcare financing in Nigeria currently involves a combination of tax revenue, out-of-pocket payments, foreign donations, and health insurance (Olakunde, 2012). Singly or in combination, these financing methods yield differing outcomes on the 
success of PHC in Nigeria. This paper examines the effects of foreign donations on the success of PHC in Nigeria and points the way forward towards better health outcomes for primary healthcare in Nigeria.

\section{PRIMARY HEALTHCARE SYSTEM IN NIGERIA}

\section{Country Sector Background}

Nigeria is situated in Sub Saharan Africa. It is Africa's most populous nation with about 200 million citizens. Its population is expected to reach $214,028,302$ by the beginning of the third quarter of the year 2020. By 2050, Nigeria's population is projected to have risen to about 390 million, making it the fourth largest population in the world (CIA, 2020). Majority of its population are between 0-14 years (NBS, 2018). National adult literacy rate in any language is $71.6 \%, 79.3 \%$ among males and $63.7 \%$ among females. $65.1 \%$ of the male gender and $50.6 \%$ of the female gender representing 57.9\% of the Adult population are literate in the English Language (NBS, 2018).

Nigeria operates a federal system of government with a national government and sub-national state and local governments. Congruously, Nigeria operates a three-tier system of health care delivery in which the federal government is responsible for the provision of health services through the tertiary and teaching hospitals, the state governments provide same through secondary hospitals, while the local governments deliver health services through the primary health care centers (PHCs).

The National Health Act 2014 is the basic national health policy on PHC and is central to providing health for all (Federal Ministry of Health, FMOH, 2014). It stipulates the creation of a basic health care provision fund (not less than $1 \%$ of federal government consolidated revenue fund). Fifty per cent of this fund will be disbursed by a National Health Insurance Scheme (NHIS) to provide a basic minimum package of health services to citizens. It requires that the remaining $50 \%$ will be used to provide essential drugs, vaccines and consumables, and infrastructure; develop human resources; and ensure emergency medical treatment at the PHC level (FMOH, 2014).

Primary health care service delivery is extremely poor in Nigeria. Nigeria's health system remains among the worst-performing globally (Ananaba, 2018). Coverage of promotive, preventive, and primary health care interventions is low. The universal health service coverage index - defined as the average coverage of tracer interventions for essential universal health coverage is a dismal 39\% (Hafez, 2018). As a result, Nigeria significantly underperforms on key health outcomes- maternal mortality rate is 243 per 100,000, Proportion of births attended by skilled health personnel is $58.6 \%$, Under Five Mortality Rate (U5MR) is 89 per 1000 births, and Neonatal mortality rate is 37 per 1000 (NDHS, 2018). These indices are unsatisfactory and have far reaching implications on health and wellbeing in Nigeria. Nigeria has a significant stock of human resources for health (HRH), but like the 57 other HRH crisis countries, the healthcare personnel-to-population ratio of 1.95 per 1,000 is too low to effectively deliver essential health services (WHO, 2020a). Also, Nigeria has repeatedly and significantly fallen short of the Abuja Declaration where it committed to devoting at least $15 \%$ of annual budgets towards improving its health sector (WHO, 2011). In 2016, government health spending was 0.6 percent as a share of GDP or just \$US11 per capita. Funding for primary health care is especially affected as the bulk of spending occurs at the central level and is focused on tertiary and secondary hospitals. 
For a primary health care system to be functional, preventive and curative, services are as germane as accessibility and closeness to the poor. A functional primary health care system should emphasize the provision of preventive and curative ambulatory services by frontline health workers in close proximity to where the poor live; disease-oriented interventions in the service of local (and national) public health goals; community-oriented interventions to tap intersectoral inputs that impact health (improved sanitation, safe drinking water); and health promotion (Shaw et al., 2015). A functional primary health care system must, among other things, provide treatment for common diseases and injuries, provide essential drugs, render basic and essential services and commodities for women, mothers and children, engage in the prevention, detection and treatment of HIV/AIDs, TB and Malaria, and perform basic and essential surgical care, especially 'first-line' surgical care pertaining to burns, wounds, and fracture management, as well as to deal with complications during birth, promote public health measures, preventive health care, promotion and education about healthy behaviors and practices, warning signs of illness, good nutrition, and the importance of immunization (WHO, 2008; Shaw et al., 2015). Present realities indicate that Nigeria is a distance away from providing universal health coverage and efficient primary healthcare.

The absence of a fully developed and functional primary health care system continues to constitute a development challenge in Nigeria. The situation threatens the achievement of health-related Sustainable Development Goals (SDGs) as well as other health objectives. Efforts by successive governments towards the realization of a functional primary health care system have often been beset by diminutive efforts at accountability, data gathering, openness and sustainability. Other limiting factors include limited institutional capacity, corruption, unstable economic, and political context and poor financing (Adinma and Adinma, 2010). The body of research on the effects of the above-mentioned factors on the development of the primary health care system in Nigeria is copious (World Bank, 2010; Aid, 2015; WHO, 2017; Gyuse et al., 2018).

Admittedly, Nigeria has not been capable of enabling the attainment of desired health outcomes. One of the major challenges facing the health sector in the country, is the weakness of the country's primary health care system. One of the major interventions to address these deficiencies in Nigeria is foreign donations. Foreign donations include financial assistance given to developing countries to support socioeconomic and health development. Yet, the effects of foreign donations are not easily discernible. Olakunde (2012) reported that between 1999 and 2007, foreign donations to Nigeria increased from US\$2.335 and US\$4.674 per capita (UNDP, 2011). By comparison, the average foreign donation in Sub-Saharan Africa (SSA) was US\$28 per capita. The share of foreign donations in primary healthcare care financing in Nigeria has been on the increase. Foreign donations were estimated as N27.87 billion (4\% of Total Health Expenditure) in 2003. This increased by 29\% to N36.04 billion (4.6\% of Total Health Expenditure) in 2004 and by just $1 \%$ to N36.30 billion (4\% of Total Health Expenditure) in 2005 (Soyibo et al., 2009). Yet, the outcomes are not commensurate with the inputs (Gyuse et al., 2018).

\section{RESEARCH PROBLEM}

Foreign donations towards improving primary healthcare have been on the increase since 1999, yet health outcomes are still uncomfortably low. Even at this low level of intervention, many of Nigeria's key health interventions such as polio eradication, routine vaccination, malaria, tuberculosis, HIV/AIDS, and maternal and child health still rely 
entirely on foreign donors, with government health funding at \$5 per citizen (Adepoju, 2019). There are legitimate reasons to be concerned about this trend because Nigeria's improving economic performance and the imminent expiry of a number of foreign funds that Nigeria benefits from imply that in the near future, Nigeria may become ineligible for a range of external health financing sources with potentially deleterious outcomes on primary health care in Nigeria.

Further, gloomy revenue projections and increasing debt burdens imply that domestic funding for primary health care in Nigeria do not seem likely to increase soon. Also, the manifestations of the effects of the added pressure by the COVID-19 pandemic on already weak health systems are likely to become obvious in the near future. Given this background, the future of primary health care in Nigeria appears bleak and portentous. Therefore, there is an urgent need for an in-depth examination of the primary health care system in Nigeria viz-a-viz foreign donations towards preparing for a future with little or no foreign aid.

Nigeria is at a crossroad. With just ten years to the 2030 deadline for the attainment of the SDGs, Nigeria is still a long distance from reaching any of the goals, especially, health related SDGs. COVID-19 is ravaging economies worldwide implying that dwindling revenues from crude oil will undermine the ability to fund health-related development interventions and meet up with national and international loan requirements. Also, traditional sources of foreign donations for healthcare improvement are battling with the crippling effects of COVID-19 on their populations and economies and this means that increasingly less will be available for foreign donations towards improving health systems across the world.

This reality dictates the need to properly review the primary health care system and revise strategies for the imminent future with little or no foreign aid. This paper examines the effect of foreign funds and donations, which are vital, needed and well-intentioned, on the development and sustainability of a functional primary health care system in Nigeria. It explores underlying issues that need to be addressed before any intervention towards a functional and sustainable primary health care system. The outputs will prove invaluable for health policy planners as they chart the course towards the attainment of health for all in Nigeria. The paper examines the effect of foreign donations in improving the primary health care system in Nigeria.

\section{METHODOLOGY}

The paper employed a comprehensive review of literature from a wide range of resources including official reports, academic journals, statistical bulletins, and online resources. In addition, qualitative methodology was applied. Two Local Government Areas were randomly selected in Ibadan to elicit information from primary healthcare policy makers and policy implementers. The two LGAs are Akinyele (Rural/Semi Urban) and Ibadan North (Urban). The study was limited to these locations due to cost and time. Furthermore, 10 Key Informant Interviews (KIIs) were conducted with policy makers and implementers. Out of this number, two were conducted in Abuja with the Director

of Primary Health Care at the Federal Ministry of Health, and NPHCDA. The remaining 8 were conducted with the Officers in Charge of the facilities visited. 
A checklist was used to capture the number by cadre mix of healthcare personnel in the selected PHCs. Qualitative content analysis was used to elicit meaning from the text of the KIIs. The qualitative data are used alongside the comprehensive literature review in order to give full understanding of the issues under study.

\section{RESULTS AND DISCUSSION}

\section{COUNTRY HEALTH PROFILE AND PUBLIC SPENDING ON HEALTH-RELATED SECTORS}

Nigeria is ranked as a low middle-income economy and its spending on the health sector has not met the $15 \%$ stated in the Abuja Declaration by the African Union in 2001 (Downie, 2017). In 2016, Nigeria's annual budget stood at 6.06 trillion naira, with N257 Billion or about $4.13 \%$ of the overall budget going to the Health sector (Downie, 2017). In 2018, Nigeria budgeted N340.46bn for health, which was 3.96 per cent of the total estimates for the year (BudgIT, 2019). In the current year, 2020, the budget for health stood at N427.3bn or about 4.5 per cent the total yearly estimate (BudgIT, 2020). Out of pocket expenditures accounts for 75.2 percent of total health expenditure and 25 percent of households spend more than 10 percent of their household consumption on health (Hafez, 2018). Table 1 below presents budgetary allocations to health relevant sectors as a share of total budget.

Table 1: Health-Relevant Sector Allocations in Annual Federal Budgets From 2016- 2020

\begin{tabular}{|c|c|c|c|c|c|c|c|c|c|c|}
\hline $\begin{array}{c}\text { Sector / } \\
\text { year }\end{array}$ & 2016 & $\begin{array}{c}\text { Share } \\
\text { of } \\
\text { budget }\end{array}$ & 2017 & $\begin{array}{c}\text { Share } \\
\text { of } \\
\text { budget }\end{array}$ & 2018 & $\begin{array}{c}\text { Share } \\
\text { of } \\
\text { budget }\end{array}$ & 2019 & $\begin{array}{c}\text { Share } \\
\text { of } \\
\text { budget }\end{array}$ & $2020^{1}$ & $\begin{array}{c}\text { Share } \\
\text { of } \\
\text { budget }\end{array}$ \\
\hline & $\mathrm{ABn}$ & $\%$ & $\mathrm{NBn}$ & $\%$ & $\mathrm{NBn}$ & $\%$ & $\mathrm{NBn}$ & $\%$ & $\mathrm{NBn}$ & $\%$ \\
\hline $\begin{array}{l}\text { Ministry of } \\
\text { Health }\end{array}$ & 250.1 & 4.1 & 308.5 & 4.1 & 356.5 & 3.9 & 372.8 & 4.2 & 381.3 & 3.5 \\
\hline $\begin{array}{l}\text { Ministry of } \\
\text { Water } \\
\text { Resources }\end{array}$ & 53.3 & 0.9 & 111.5 & 1.5 & 155.0 & 1.7 & 100.5 & 1.1 & 85.1 & 0.8 \\
\hline $\begin{array}{c}\text { Total } \\
\text { Budget }\end{array}$ & $6,060.7$ & 100.0 & 7,441.2 & 100.0 & $9,120.3$ & 100.0 & $8,916.9$ & 100.0 & $10,810.8$ & 100.0 \\
\hline
\end{tabular}

Source: Budget office of the Federation.

${ }^{1}$ The budget for 2020 was revised further down due to the sharp decline in oil prices because of the COVID-19 pandemic

Across the five years between 2016-2020, budgetary allocation to the health sector have been increasing but was consistently less than the $15 \%$ minimum set at the Abuja declaration. This poor budgetary allocation to the health sector over the years necessitate foreign donations in health care delivery and improvement in Nigeria. 


\section{THE PRESENT STATE OF PRIMARY HEALTH CARE IN NIGERIA}

Globally, and as in Nigeria, achieving universal health coverage as conceived under the Sustainable Development Goals (SDGs) involves taking health service delivery to all parts of the globe where people can be found. This also is the vision of World Health Organization for achieving all health-related SDGs (WHO, 2018). Nigeria has a large proportion of its population living in rural areas where access to basic health care system is crucial. The geographic configuration of many of the rural settlements and villages make access to these villages and settlements a challenge. Poverty, distance, bad road networks, and high cost of travel may limit the desire to seek medical services in urban or more developed areas by settlers in hard-to-reach villages. Hence, reaching people in hard-to-reach areas requires the establishment of a health care system that caters to the needs of a relatively small population and which delivers essential preventive and curative medical services to the communities served at an affordable and sustainable cost. To this end, primary health care is widely recognized as the most cost-effective way to reach the goal of universal health coverage and address comprehensive health needs close to people's homes and communities (WHO, 2019).

Primary healthcare in Nigeria is grossly inefficient and inadequate to provide quality health services for Nigeria's teeming population. Of the 30,000 primary health care centres across the country, only a measly $20 \%$ are functional (Uzochukwu et al., 2015). Demographic indicators highlight the need for a developed, functional and far reaching primary health care System. Extreme poverty and illiteracy rates are high. In 2018, Nigeria attained the unenviable designation of "poverty capital of the year", with 86.9 million Nigerians living in extreme poverty (Quartz, 2018). That represents close to $50 \%$ of its entire population. If the current trajectory is unchanged, an estimated 110 million will be living in extreme poverty in Nigeria by the year 2030 (Kharas et al., 2019). The widespread poverty and high level of illiteracy in Nigeria affects their access to quality and healthy nutrition, thereby leaving them susceptible to diseases. Access to basic amenities such as portable water and electricity is low in poor and rural communities while sanitation is poor and open defecation is prevalent. The high and growing rate of extreme poverty coupled with a high level of illiteracy in Nigeria makes the case for an efficient and sustainable primary Health Care System even more urgent. It is projected that developing a functional and sustainable primary health care system in low- and middle-income countries, such as Nigeria, would save at least 60 million lives and increase average life expectancy by 3.7 years by 2030 (WHO, 2019).

Nigeria currently has some of the worst health outcomes in the world, due in part to the poor state of primary health care services, which are characterized by a lack of coverage (especially in rural areas), inadequate health facilities and high user fees (Uzochukwu et al., 2015). Also, across PHCs, health workers are untrained and trained workers lack a thorough grasp of the modern concept of PHC (Abdulraheem et al., 2012). The absence of a fully functional primary health care system has resulted in a large number of people seeking medical services, that should be offered by the primary health care system. Nigeria needs a functional primary health care system in order to forestall the collapse of the already overburdened secondary and tertiary health facilities in the country. The additional burden placed on secondary and tertiary health institutions in Nigeria amplifiers fundamental challenges towards service delivery and stretches beyond limits the merger resources of these underfunded institutions. Hence, failure to develop a functional and sustainable primary health care system in Nigeria portends the collapse of already weak public health system in Nigeria. 
Another reality of primary healthcare in Nigeria is that there is a shortage of skilled healthcare personnel in the primary healthcare system. This deficiency is obvious in shortage of various cadres of health personnel and the inability of the primary health care system to meet up the minimum standards of cadre mix as stipulated by the Federal Ministry of health.

Table 2: Number of Workers Employed in 8 PHCs in 2 LGAs in Oyo State Compared to the Minimum Standard

\begin{tabular}{|c|c|c|c|c|c|c|c|c|c|c|}
\hline & $\begin{array}{c}\text { FMOH } \\
\text { Standard }\end{array}$ & $\begin{array}{c}\text { PHC } \\
1\end{array}$ & $\begin{array}{c}\text { PHC } \\
2\end{array}$ & $\begin{array}{c}\text { PHC } \\
3\end{array}$ & $\begin{array}{c}\text { PHC } \\
4\end{array}$ & $\begin{array}{c}\text { PHC } \\
5\end{array}$ & $\begin{array}{c}\text { PHC } \\
6\end{array}$ & $\begin{array}{c}\text { PHC } \\
7\end{array}$ & $\begin{array}{c}\text { PHC } \\
8\end{array}$ & Avg \\
\hline Medical Officer & 1 & 0 & 0 & 1 & 0 & 0 & 0 & 1 & 0 & 0.25 \\
\hline $\begin{array}{l}\text { Community Health } \\
\text { Officer }\end{array}$ & 1 & 4 & 3 & 3 & 0 & 1 & 2 & 2 & 1 & 2.00 \\
\hline Nurses and Midwives & 4 & 2 & 0 & 2 & 0 & 0 & 2 & 2 & 2 & 1.25 \\
\hline CHEWs & 3 & 2 & 2 & 4 & 1 & 0 & 1 & 2 & 2 & 1.75 \\
\hline Pharmacy Technician & 1 & 0 & 1 & 0 & 0 & 0 & 0 & 1 & 0 & 0.25 \\
\hline Junior CHEWs & 6 & 0 & 1 & 0 & 0 & 0 & 1 & 0 & 2 & 0.5 \\
\hline Environmental Officer & 1 & 0 & 3 & 0 & 1 & 1 & 1 & 0 & 0 & 0.75 \\
\hline Medical Record Officer & 1 & 1 & 1 & 0 & 0 & 0 & 1 & 2 & 1 & 0.75 \\
\hline Laboratory Technician & 1 & 1 & 1 & 0 & 0 & 0 & 0 & 0 & 0 & 0.25 \\
\hline $\begin{array}{l}\text { Health } \\
\text { Attendant/Assistant }\end{array}$ & 2 & 1 & 2 & 1 & 1 & 1 & 3 & 2 & 2 & 1.625 \\
\hline Security Personnel & 2 & 1 & 0 & 1 & 0 & 0 & 1 & 0 & 1 & 0.5 \\
\hline $\begin{array}{l}\text { General Maintenance } \\
\text { Staff }\end{array}$ & 1 & 0 & 0 & 0 & 0 & 1 & 0 & 0 & 0 & 0.125 \\
\hline Total & 24 & 12 & 14 & 12 & 3 & 4 & 12 & 12 & 11 & 10 \\
\hline
\end{tabular}

The average number by cadre mix in the selected PHCs was used to compare with the minimum standard set by the federal ministry of health. On the average, each cadre of healthcare personnel for primary healthcare is understaffed, and the cadre mix is below the minimum standards set by the federal ministry of health. This indicates serious deficiencies in personnel required for the primary health care system in Nigeria.

Each year, Nigeria loses thousands of children to preventable diseases such as Pneumonia. Nigeria has the highest number of child deaths as a result of Pneumonia. This is even as the disease can be prevented with vaccines, and easily treated with low-cost antibiotics that should be available in primary health centers (UNICEF, 2020). Other health problems such as malaria continue to ravage with an estimated 100 million cases and over 300,000 deaths per year in Nigeria. Malaria contributes to an estimated $11 \%$ of maternal mortality. Other common sicknesses that claim lives of Nigerians each year include HIV/AIDS, diaorrhea, cholera, typhoid fever, dengue fever, yellow fever, rabies, and meningococcal meningitis. Many of these diseases can be prevented and managed at the primary health care unit. 
A functional and sustainable primary health care system is therefore germane in the reduction of child and maternal mortality and deaths from preventable and common diseases.

\section{CONSTRAINTS TO PROPER FUNCTIONING OF PRIMARY HEALTHCARE SYSTEM IN NIGERIA}

In addition to the constraint of poor public spending on the health sector in Nigeria, qualitative analysis revealed a number of other constraints to proper functioning of PHC in Nigeria. These factors were highlighted from the interviews with key stakeholders in the Federal Ministry of health (FMOH), the National Primary healthcare Development Agency (NPHCDA) and Primary Healthcare Centres visited. The factors identified are:

1. Inconsistent political will to invest in public health care.

"it is expected that every developing country should allocate at least $26 \%$ of its budgetary allocation to health. The last one (budget) I checked in 2017 is not up to about 7\%." NPHCDA

"There is no agenda for health. In fact the politicians in Nigeria don't even care about health. It is true that previous initiatives have failed because the political class do not appreciate the service providers at that level. And until that is done, our health sector cannot improve." FMOH

"There is poor political will, there is inadequate funding. Look at all the indices on MDGs. There is none you can achieve without adequate funding, without adequate and proficient human resources to guide it. So once you don't have the required inputs, there can be no definable output." OIC Sango PHC

"But while you have the issue of political sentiments. Political differences, party lines and so on, you do not sometimes get the expected partnership and collaboration. And I believe this is key to why the MDGs goals were not achieved." NPHCDA

"In this political era, I think health is not there target, they have not really hit their target in terms of health."

\section{OIC Idi Ogungun PHC}

2. Failure to expand primary healthcare to meet up with the geometric growth of the population.

"The first factor we always flog is corruption. Let me say it clearly. As our population is increasing, all our facilities and equipment are supposed to increase along same proportion. If we are increasing in a geometric pattern, our facilities should increase in geometric pattern. Today by calculations, projections and estimations we are about 200 (million). if you go in details, where are we in terms of our social security and improvements in our social safety nets? We are not there." NPHCDA 
3. Shortage of staff, lack of equipment and free drugs

"The previous efforts did not fail in all Primary Health Care. But the majority of Primary Health Care that it failed maybe it is due to shortage of staffs, equipment and all the drugs is not available because most of our patients depend on... They just want everything to be free. In case there are no human resources, drugs and the people there don't know how to get the drugs, they might not want to patronize the health center."

\section{IDI 4}

\section{NATIONAL HEALTH ACT AND PRIMARY HEALTH CARE FINANCING}

The National Health Act was signed into law in the year 2014. A key component of the National Health Act is the establishment of the Basic Health Care Provision Fund (BHCPF), which aims to extend Primary Health Care (PHC) to all Nigerians by substantially increasing the level of financial resources to PHC services (Uzochukwu et al., 2015). The National Health Act aims at providing primary health care facilities much needed operational budgets to improve their overall capacity to provide basic services as primary health centers have historically received little to no operating budget and frequently lack basic amenities, equipment, and drugs to be able to deliver quality services (World Bank, 2018).

Under the National Health Act, the BHCPF Funding of the BHCPF would be derived from contributions including: an annual grant from the Federal Government of Nigeria of not less than one per cent (1\%) of its Consolidated Revenue Fund (CRF), grants by international donor partners and funds from any other source (FGN, 2016). Other sources of funding include funds from grants received from local or international donors and innovative taxes, while requiring a 25\% counterpart funding of PHC projects by States and Local governments as a prerequisite for accessing funds from BHCPF (Uzochukwu et al., 2015). It also provides for how funds committed to the BHCPF would be disbursed: Half of the Fund will be used to provide a basic package of services in PHC facilities through the National Health Insurance Scheme (NHIS); 45\% will be disbursed by the National Primary Health Care Development Agency (NPHCDA) for essential drugs, maintaining PHC facilities, equipment and transportation, and strengthening human resource capacity and the final $5 \%$ will be used by the Federal Ministry of Health (FMOH) to respond to health emergencies and epidemics. (Uzochukwu et al., 2015; Downie, 2017). In addition, as a statutory transfer, the BHCPF ensures that funding for PHCs would be safeguarded guaranteeing that any unused funds that arise because of low demand, poor uptake, delays in the release of funds or in the receipt of claims from providers will be rolled-over to next year's fund (World Bank, 2018).

A breakdown of the percentages allocated to NHIS, NPHCDA and the FMoH show that the intent of the $\mathrm{BHCPH}$ is to accelerate the improvement of the health of Nigerians. In this regard, part of the funds managed by NHIS (50\% of BHCPF) was for the provision of the Basic Minimum Package of Health Services (BMPHS) for Nigeria which shall consist of six (6) interventions; four (4) for Maternal Health, one (1) for Cardiovascular Disease and urinalysis test. Access to BMPHS would be free for all Nigerians. The $45 \%$ managed by NPHCDA is broken down into $20 \%$ for essential drugs, vaccines \& consumables in PHCs, 15\% to Provision and Maintenance of Facilities, including equipment and transportation in PHCs and $10 \%$ to the development of human resources at the PHCs (FGN 2016).Implementation of allocation of the BHCPF was to begin in rural areas in order to reach the poorest of the poor 
with essential medical services thus providing greater financial protection to the poorest and sickest households (Hafez, 2018).

One major challenge encountered in the implementation of the National Health Act (NHA) has been a lack of funding. The BHCPF has not been funded (Hafez 2018). Funding for BHCPF, a major component of NHA, was not part of the 2015, 2016 budget of the Federal Government of Nigeria (Downie, 2017). There is also the lack of detailed data on health spending and resource flows, including the cost and use of health services, needed in planning and advocating for investment into the health sector (World Bank, 2018). Hence, the challenge of the primary health care system in Nigeria is not the absence of a legal framework for the development of a functional and sustainable primary health care system as there are many laudable provisions towards such development in the National Health Act (2014).

It is worthy of note that while foreign donations are not designated for use in the recruitment of healthcare personnel, they could have been used for health systems strengthening such as provision of health infrastructure and other health related interventions in remote and rural areas across Nigeria. Doing so would have freed up funds from annual budgetary allocations for the recruitment, training and re-training of health care personnel in the primary health care system.

\section{AMOUNT AND EFFECTS OF FOREIGN DONATIONS ON PRIMARY HEALTH CARE OVERVIEW OF FOREIGN FUNDS FOR THE DEVELOPMENT OF THE HEALTH CARE SYSTEM IN NIGERIA}

Foreign funds in the form of donations and grants have proved very useful in improving health care outcomes in Nigeria. In fact, the health sector in Nigeria receives the attention of many international donor agencies and governments and is sustained by foreign funds (Downie, 2017). Many interventions supported by foreign donors facilitate the treatment and management of diseases such as Malaria, Tuberculosis (TB) and HIV/AIDS. Such interventions, running into millions of dollars have provided testing kits, drugs, management training for health workers and policy development. The table below presents foreign donations towards improving health care in Nigeria from 2010-2017.

Table 2: Foreign Donations in Support of the Nigeria Health Sector, 2010-2017

\begin{tabular}{lcc}
\hline Year & Amount \$ & \% of Total Foreign transfer \\
\hline 2010 & 7785491 & 77 \\
2011 & 4628523 & 23.3 \\
2012 & 3048483 & 19.5 \\
2013 & 8116466 & 28.3 \\
2014 & 24432623 & 34.9 \\
2015 & 16322655 & 10.3 \\
2016 & 39439790 & 8.4 \\
2017 & 32011695 & 3.4 \\
\hline
\end{tabular}

Source: UNOCHA, 2018. 
Nigeria's return to democratic civilian rule in 1999 ushered in new partnerships and commitments to growth and development in all aspects of the socioeconomic life of its citizens. Foreign donations towards improving health outcomes through improvements in the primary health care systems in Nigeria has progressively increased since 2010. Despite this, health outcomes are still unsatisfactory. Maternal mortality is one of the highest in the world at 576 deaths per 100,000 live births; one in eight children die before reaching their fifth birthday; and 25 percent of households spend more than 10 percent of their household consumption on health. Health personnel are grossly inadequate to provide decent primary healthcare. It is a common knowledge that most PHCs in Nigeria function with a cadre mix that is far below the minimum mix for standard care. Poor staffing of the primary health care centres is largely blamed on poor funding. Most governments at the local level do not give attention to the staffing of the PHCs facilities and where staffs are employed, they are poorly paid, or their salaries are not paid for many months. Such situation reduces the number of competent persons that would seek employment in the primary health care system rather than private practice or clinics.

\section{IMPACT OF FOREIGN FUNDS ON THE DEVELOPMENT OF THE PRIMARY HEALTH CARE SYSTEM IN NIGERIA}

While foreign donations have had major positive impacts on health care outcomes for millions of Nigerians, it is not definitely clear what impact it has on the development of a functional and sustainable health care system for Nigeria. This is because foreign donations do not address the root causes of factors that hold back the development of the primary health care system in Nigeria. Instead, the availability of foreign funds and the funding objectives create conflicts of interests. Two of these very salient issues are the perpetuation of a non-committal attitude towards increasing domestic spending on health, and neglect of health system strengthening.

\section{PERPETUATION OF A NON-COMMITTAL ATTITUDE TOWARDS INCREASED DOMESTIC SPENDING ON HEALTH}

Domestic spending on Health has been low in Nigeria. In fact, Nigeria is one of the countries with least public spending on health (Ananaba et al., 2018) in the world. As a signatory to the Abuja declaration, Nigeria is expected to fund health care by up to $15 \%$ of the annual national budgets However, till date, Nigeria has never met the pledged funding. The 2020 budget devotes $3.5 \%$ to the health sector (BudgIT, 2020). The statutory $1 \%$ of consolidated revenue encoded in National Health Act (2014) for Basic Health Care Provision Fund BHCPF, which is a domestic legal provision for the development of a functional and sustainable primary health care system in Nigeria for better health care outcomes to all Nigerians, was willingly passed and signed into law in 2014 by the Nigerian government. The BHCPF remained unfunded from 2014 to 2018. Also, as the COVID-19 pandemic necessitated a review of the 2020 national budget, BHCPF was significantly reduced by $\mathrm{N} 44.4 \mathrm{bn}$ to $\mathrm{N} 25.5 \mathrm{bn}$, a decrease of more than 42.5 per cent while allocations to non-critical sectors were only reduced by $10 \%$ (Punch Newspaper, June 3, 2020). These trends point towards a weak commitment towards improving primary health care.

This non-committal attitude towards domestic spending on health could be connected with the availability of alternate sources of funding- foreign donations. Millions of dollars in foreign funds for health interventions seems to 
justify the low budgetary allocation to. If the trend persists, it may become fashionable for sub national governments to follow the same course. Indeed, critics of donor support argue that many governments have abdicated their primary responsibilities to donor partners (Ufuoma, 2013).

\section{NEGLECT OF HEALTH SYSTEM STRENGTHENING}

Foreign donations in the health sector can either be used for health systems support, or health system strengthening or a combination of both. Given the current realities of the primary health care systems in Nigeria, Nigeria requires tangible investments in health system strengthening (HSS). HSS involves the process of identifying and implementing the changes in policy and practice in a country's health system and any array of initiatives and strategies that improves one or more of the functions of the health system and that leads to better health through improvements in access, coverage, quality, or efficiency (WHO, 2020).

On the contrary, evidence exists that donor assistance to the health sector have been mainly in the health systems support area, rather than for health systems strengthening (Shaw et al., 2015. Hence, foreign funds were often available for disease management interventions, while spending on HSS in support of PHC Delivery in Nigeria declined dramatically over time (Shaw et al., 2015). A 2011 study reports that 57\% of total health sector assistance was for sexually transmitted diseases and HIV/AIDS, whereas Nigeria's burden of diseases associated with HIV/AIDS/TB was estimated to be less than 5\% (Ananaba, 2018).

Even when and where their foreign donations are committed to HSS, it has been unclear whether the scaledup investment in programs to strengthen the existing fragile health systems of many developing countries, such as Nigeria, is producing the required outcomes in creating self-reliance in the benefiting countries (Ufuoma, 2013).

\section{CONCLUSION}

The paper investigated the effects of foreign donations on primary healthcare in Nigeria. Primary health care in Nigeria is currently inefficient and is incapable of achieving health related sustainable development goals. Given the low level of government funding of health sector, particularly the PHC system over the years, foreign donations have been increasing and have become essential for the development of a functional and sustainable primary health care in Nigeria. This challenge becomes more urgent against the background of projected declines in foreign donations towards improving healthcare because of a number of socioeconomic factors. Foreign donations have created two major spillover issues: weakening of commitment to domestic funding and neglect of health system strengthening. Foreign donations cannot be a replacement for increased domestic spending on public health. Increased domestic funding must be made a prerequisite for foreign funds. Increase in domestic funding for health along with the strengthening of the health system in Nigeria will ensure that when donor funds are no longer available, Nigeria's primary health care system would be ready, and able to deliver quality health care to Nigerians. 


\section{REFERENCES}

Abdulraheem, B. I., Olapipo, A. R. and Amodu, M. O. (2012). Primary health care services in Nigeria: Critical issues and strategies for enhancing the use by the rural communities. Journal of Public Health and Epidemiology 4(1): 5-13.

Alonge, $2020 \mid 97$

AJHSE 1(2)

Adepoju P. (2019). Nigeria Faces a Health Financing Cliff Edge. Online Publication, Global Health, Devex. Available at https://www.devex.com/news/nigeriafaces-a-health-financing-cliff-edge-93968

Adinma, E. D. and Adinma, B. D. J. (2010). Community based healthcare financing: An untapped option to a more effective healthcare funding in Nigeria. Nigerian Medical Journal 51(3):95.

Aid, C. (2015). Assessment of primary health Centres in selected states of Nigeria: summary report of findings from Christian Aid supported communities in Anambra, Benue, Kaduna, plateau states and the Federal Capital Territory (FCT). Abuja: Christian Aid. Retrieved on September 20, 2020 from: https://www.christianaid.org.uk/sites/default/files/2016-11/Summary-Report-AssessmentPrimary-Healthcare-Centres-Nigeria-Jul-2015.pdf

Ananaba, A., Sadiq, F.U. and Piron, L. (2018). Health Financing in Nigeria: Retrieved August 22, 2020 from: http://www.perlnigeria.net/storage/casestudies/June2018/vfspJJOnqo 5EVzDF8DnT.pdf.

BudgIT (2019). Approved Budget Analysis. Available https://yourbudgit.com/wpcontent/uploads/2019/07/2019-Approved-Budget-Analysis.pdf

BudgIT (2020). 2020 Budget: Analysis and Opportunities. Available at: https://yourbudgit.com/wpcontent/uploads/2020/03/2020-Budget-Analysis.pdf

CIA (2020). The World Factbook 2020. Washingtin DC: Central Intelligence Agency. Assessed on July 29. 2020 from https://www.cia.gov/library/publications/resources/the-world-factbook/index.html

Devex (2019). Nigeria faces a health financing cliff edge. Available at: https://www.devex.com/news/nigeria faces-a-health-financing-cliff-edge-93968

Downie, R. (2017). Promoting Accountability in Nigeria's Health System. A report for the CSIS Global Health Policy Center. Center for Strategic \& International Studies. Retrieved 12 ${ }^{\text {th }}$ August, 2020 from: https://www.researchgate.net/publication/314246094_Promoting _Accountability_in_Nigeria\%27s_Health_System

Drouin, A. (2007). Methods of financing health care: A rational use of financing mechanisms to achieve universal coverage. In World Social Security Forum, Moscow pp. 10-15.

Federal Ministry of Health (2014). Federal Republic of Nigeria National Health Act 2014. Government Notice No. 208. Federal Republic of Nigeria Official Gazette 101: A139-A172.

FGN (2016). Federal Government of Nigeria. Minimum Standards for Primary Health Care in Nigeria. National Primary Health Care Development Agency. 1-69 
Gyuse, A. N., Ayuk, A. E. and Okeke, M. C. (2018). Facilitators and barriers to effective primary health care in Nigeria. African Journal of Primary Health Care \& Family Medicine 10(1): e1-e3. https://doi.org/10.4102/phcfm.v10i1.1641

Hafez, R. (2018). Nigeria Health Financing System Assessment. Health, Nutrition and Population Discussion Paper; World Bank, Washington, DC. () World Bank. Available at: https://openknowledge.worldbank.org/handle/10986/30174 License: CC BY 3.0 IGO.

Kharas, H., Hamel, K. and Hofer, M. (2018). Rethinking global poverty reduction in 2019. Blog. Future Development at Brookings.

National Bureau of Statistics. (2018). Demographic statistics bulletin. May, Abuja, 1-26

NDHS (2018). Nigeria Demographic and Health Survey 2018. Abuja, Nigeria, and Rockville, Maryland, USA: NPC and ICF, $1-488$

Olakunde, B. O. (2012). Public health care financing in Nigeria: which way forward? Annals of Nigerian Medicine 6(1): 4 - 10

Quartz (2018). Nigeria has become the Poverty Capital of the World. A Dim Outlook Article. Quartz Available at https://qz.com/africa/1313380/nigerias-has-the-highest-rate-of-extreme-poverty-globally/

Shaw, R. P., Wang, H., Kress, D. and Hovig, D. (2015). Donor and domestic financing of primary health care in low income countries. Health Systems and Reform 1(1): 72-88.

Soyibo, A., Olaniyan, O. and Lawanson, A. O. (2009). National Health Accounts of Nigeria 2003-2005: Incorporating Sub-National Health Accounts of States. Report submitted to the Federal Ministry of Health Abuja. Cited by Olakunde, 2012.

The World Bank, (2010). Improving primary health care delivery in Nigeria: evidence from four states. World Bank Publications.

Ufuoma, O. (2013). A New and Simple Method of Solving Large Linear Systems: Based on Cramer's Rule but Employing Dodgson's Condensation. In Proceedings of the World Congress on. Engineering and. Computer. Science 1, $23-25$

United Nations Development Programme (2011). MDGs Needs Assessment and Financing Strategy for Nigeria: Policy Brief. Available at http://www.ng.undp.org/mdgs/policy_brief.pdf.

UNOCHA (2018). Annual Available at: https://www.unocha.org/sites/unocha/files/OCHA2018AnnualReport.pdf

Uzochukwu, B., Onwujekwe, O., \& Mbachu, C. (2015). Implementing the Basic Health Care Provision Fund in Nigeria: a framework for accountability and good governance. London, UK: RESYST (Resilient and Responsive Health Systems) Research Consortium.

World Health Organization (2008). Primary Healthcare. Now More than Ever. World Health Report. Available at: https://www.who.int/whr/2008/whr08_en.pdf 
World Health Organization (2019). Primary Health Care. Available at: https://www.who.int/healthtopics/primaryhealth-care\#tab=tab_1

World Health Organization (2019). Primary Health Care. Retrieved on $23^{\text {rd }}$ September, 2020 from: https://www.who.int/health-topics/primaryhealth-care\#tab=tab_1

World Health Organization (2020a). Health Systems Strengthening Glossary. Retrieved on June 3, 2020 from: https://www.who.int/healthsystems/hss_glossary/en/index5.html

World Health Organization. (2008). Primary health care: now more than ever. World Health Organization. Retrieved on $24^{\text {th }}$ September 2020 from: https://www.who.int/whr/2008/08_overview_en.pdf

World Health Organization. (2011). The Abuja declaration: ten years on. Geneva: World Health Organization.

World Health Organization. (2018). A vision for primary health care in the 21st century: towards universal health coverage and the Sustainable Development Goals (No. WHO/HIS/SDS/2018.15). World Health Organization. 